\title{
Ordem e Justiça na Sociedade Internacional pós-11 de Setembro
}

\author{
Order and Justice in the International Society \\ after September 11
}

EMERSON MAIONE DE SOUZA*

Rev. Bras. Polit. Int. 52 (1): 133-148 [2009]

\section{Introdução}

Neste artigo, visa-se analisar como a abordagem da Escola Inglesa tem examinado a política internacional do pós-11 de Setembro. Normalmente, a Escola Inglesa é identificada por sua ênfase ao conceito de sociedade internacional. Conforme desenvolvido por Hedley Bull (1995: 13), tal conceito pressupõe a existência de um grupo de Estados que se consideram ligados por certos valores e interesses comuns. Seu relacionamento acontece, por um conjunto comum de regras, e instituições comuns. Essa ênfase demonstra as preocupações normativas dos membros da Escola Inglesa com as regras, normas, leis e princípios de legitimidade que sustentam a ordem mundial.

Nesse sentido, ao se analisar um determinado contexto internacional a Escola procura focar na prática, ou seja, os significados e as justificações que os agentes dão para suas ações. E ao mesmo tempo em que procura enxergar a historicidade de tais práticas, busca apoio na teoria política internacional para informar sobre as bases dos julgamentos morais destas ações e sobre o estado em que estamos (Dunne, 2005a: 170). Por isso a ênfase de Martin Wight (1991) em que as três tradiçóes de pensamento (Racionalista, Revolucionista e Realista) refletiam a interpenetração entre a teoria e a prática da política: a teoria, por meio da análise e da classificação de escritos dos teóricos das respectivas tradições; a prática, por meio da análise dos discursos e das ações de diversos estadistas.

A sociedade internacional reflete um ordenamento precário e difícil de ser mantido, mesmo quando suas instituições funcionam adequadamente. Ela varia não somente de acordo com as mudanças na distribuição de poder, mas,

\footnotetext{
* Mestre em Relaçóes Internacionais pela Pontifícia Universidade Católica do Rio de Janeiro - PUC-RIO e professor de Relaçôes Internacionais no Centro Universitário Metodista do Rio (Bennett), na Universidade Estácio de Sá e pesquisador do Grupo de Pesquisa sobre a Ordem Mundial Comparada da Universidade Federal do Rio de Janeiro - UFRJ (emersonmaione@terra.com.br).
} 
principalmente, com as mudanças dos princípios de legitimidade que estão em sua base. Diante da afirmação de Bull (1995: 308) de que as bases normativas da ordem internacional precisam ser constantemente reavaliadas, o emergente padrão de crise e guerra iniciado pelo ataques terroristas em Nova York e Washington em setembro de 2001 e sustentado pelas de guerras contra o Afeganistão e o Iraque, provê um novo contexto em que deve ser reavaliada a afirmação da Escola Inglesa de que a sociedade internacional é um importante elemento na realidade da política mundial (Dunne, 2003: 303). O objetivo deste artigo é examinar criticamente alguns trabalhos recentes de autores da Escola Inglesa afim analisar como tal abordagem pode nos ajudar a entender a atual sociedade internacional. Ver como ela está respondendo aos principais desafios políticos da atualidade.

$\mathrm{O}$ artigo está dividido em duas partes. Na primeira, examinaremos alguns desenvolvimentos sobre a questão da justiça na atual Escola Inglesa. Na última parte serão analisados os trabalhos de autores que usam o arcabouço teórico da Escola Inglesa para examinar os impactos da hegemonia americana na sociedade internacional pós-11 de Setembro.

\section{Ordem e Justiça}

O objetivo nesta seção é examinar alguns desenvolvimentos sobre a questão da justiça na atual Escola Inglesa a fim de poder, na outra seção, examinar as possibilidades que os autores desta Escola vislumbram sobre o assunto no atual ordenamento unipolar.

Um ponto importante a se levantar sobre as análises e comentários feitos sobre a Escola Inglesa é que a centralidade das questôes morais contida em seus escritos foi pouco apontada pelos comentadores. Talvez porque focalizaram em demasia a questão da ordem, não dispensando a devida atenção a outros pontos fundamentais da Escola Inglesa, como, por exemplo, a ênfase em estruturas intersubjetivas, ao invés de estruturas materiais. Apesar disso, recentemente, com a proeminência das chamadas teorias normativas, o quadro tem mudado, relativamente: leituras mais acuradas de seus trabalhos têm sido feita e, consequentemente, mais atenção tem sido dada a tais aspectos da Escola Inglesa (Souza, no prelo). ${ }^{1}$

Para analisarmos os aspectos normativos que a Escola Inglesa destaca, em primeiro lugar, temos que fazer referência ao debate entre as concepções pluralista e solidarista da sociedade internacional, distinção esta feita por Hedley Bull (1966).

1 Para Bull (1991: xi), a centralidade das questōes morais também era uma das características dos escritos de Martin Wight: "Wight colocava estas questôes no centro da sua pesquisa”. Um exemplo de comentador atual que destaca o lado normativo da Escola Inglesa é Reus-Smit (2002 e 2005). Para este autor, as questões normativas ocupam lugar central na Escola Inglesa. Por isso destaca que falar da Escola Inglesa sem mencionar este aspecto central é apenas reproduzir estereótipos empobrecedores. Aqui não é o lugar para uma revisão da literatura, empreendi uma análise dos trabalhos que destacam esses pontos da Escola Inglesa, ver (Souza, 2003 e no prelo). 
Estas duas concepções representam duas visões sobre a possibilidade da promoção da justiça na política global e pontuam a maioria dos debates sobre tais pontos na Escola Inglesa.

Normalmente os termos do debate dentro da Escola Inglesa são os seguintes: o pluralismo descreve sociedades internacionais "tênues" (thin) onde são poucos os valores compartilhados e onde o foco principal é desenvolver regras de coexistência dentro de um quadro de soberania e não-intervenção; o solidarismo, por sua vez, descreve sociedades internacionais "densas" (thick) onde uma maior gama de valores é compartilhada e as regras não são apenas de coexistência, mas também sobre a busca de ganhos comuns e o gerenciamento de problemas coletivos (Buzan, 2004: 58-9). Barry Buzan (2004: 59) destaca que para evitarmos concepções dicotômicas deveríamos pensar sobre o pluralismo e o solidarismo como pontas de um mesmo espectro. Se o solidarismo é compreendido como sendo sobre a densidade das normas, regras e instituições que os Estados decidem criam para gerenciar suas relações, então pluralismo e solidarismo simplesmente ligam posiçõos em um espectro e não são necessariamente contraditórios. Dessa forma, eles representam diferenças de grau e não posiçōes contraditórias.

Dando continuidade à tradição de teorização normativa dentro da Escola Inglesa, Andrew Hurrell quer explorar a relação entre ordem e justiça. Para ele, a estrutura normativa da sociedade internacional desenvolveu-se de modo em que há agora uma cada vez mais densa e integrada rede de instituições e práticas compartilhadas em que as expectativas sociais de justiça e injustiça globais tornaram-se mais estabilizadas. Mas, ao mesmo tempo, nossas principais instituições sociais internacionais continuam a constituir uma ordem política deformada, principalmente por causa das extremas disparidades de poder que existem tanto na sociedade internacional quanto na mundial. Essa combinação de densidade e deformidade molda o modo como pensamos a relação entre ordem e justiça (2003: 36). Se, por um lado, a densidade nos impede que retrocedemos à ordem minimalista do pluralismo; por outro, a deformidade somada às "qualidades hegemônicas da ordem internacional contemporânea não necessariamente marcam o fim dos comprometimentos com princípios cosmopolitas, mas podem ter um efeito negativo de longo prazo na sua consolidação" (Linklater e Suganami, 2006: 195).

Hurrell observa que conforme a ordem jurídica no pós-Guerra Fria tem se desenvolvido em direção ao solidarismo, uma importante ambigüidade começa a surgir sobre a visão dos Estados como os principais agentes da ordem mundial:

No mundo pluralista, os Estados podiam ser entendidos como "agentes" apenas no sentido daqueles agindo, exercendo poder e fazendo algo para si mesmo: "O direito das naçôes é o direito dos soberanos", como Vattel afirmou. Mas a expansiva agenda normativa do solidarismo trouxe um segundo e diferente significado de agência: a idéia de um agente como alguém que age por, ou em benefício de, outrem. Dentro da ordem solidarista os Estados não agem mais para si mesmos como soberanos, 
mas antes, em primeiro lugar, como agentes para os indivíduos, os grupos, e as comunidades nacionais que eles supostamente devem representar - daí a mudança em direção à soberania como responsabilidade - e, em segundo, como agentes ou intérpretes de alguma noção de bem público internacional e algum conjunto de normas centrais contra as quais o comportamento do Estado deve ser julgado e avaliado (2003: 40).

Hurrell argumenta ainda que a mudança envolveu não apenas instituições interestatais mas também presenciou a emergência de estruturas transnacionais de governança. Como exemplo cita o crescente papel das firmas e ONGs no processo de criação das normas internacionais.

Sobre as possibilidades de justiça internacional nos tempos atuais, Hurrell, baseado em seus estudos sobre a globalização, destaca a necessidade da diminuição da desigualdade econômica e a formação de um contexto em que os mais necessitados percebam alguma vantagem no sistema. Faz alguns apontamentos. Primeiro, parece muito improvável que uma única ideologia ou visão de mundo poderá prover um quadro englobante ou meta-narrativa para os valores e a ética no século XXI - liberalismo global, por exemplo. Ao invés disso, debate, deliberação e contestação sobre questões de justiça terá lugar em uma ampla gama de esferas e domínios envolvendo uma miríade de atores: Estados, ONGs, firmas, organizações internacionais. Segundo, os participantes continuarão a vir de uma variedade de contextos culturais, religiosos e lingüísticos. Você não precisa acreditar em choques de civilização ou em incomensurabilidade para acreditar que a diversidade humana e conflitos de valores permanecem importantes e que perspectivas sobre questóes de ordem e justiça internacional variam enormemente de uma parte do mundo para outra. Complexidade cultural e histórica também torna difícil generalizar leis universais a partir de casos particulares: uma grande parte dos debates sobre valores e ética no século XXI será necessariamente rico em análise de contextos e interpretativo (2003: 44).

Por fim, para Hurrell justiça e eqüidade em relação ao processo e aos procedimentos é mais importante do que justiça e eqüidade em questóes de substância pelo fato de ser o mais provável para se alcançar acordos substantivos dado a profundidade dos conflitos de valores e, ainda, a facilidade com que o direito internacional e as instituições são contaminados pelos interesses e valores dos mais poderosos. A forma mais viável de comunidade moral global continuará a ser aquela construída em torno de alguma noção mínima de processo justo. Por quê? Ele responde que, em primeiro lugar, o quadro de entendimentos e cultura moral compartilhado que realmente conseguiu desenvolver-se foi criado dentro da sociedade internacional; segundo, e mais fundamental, por causa da universalidade das idéias sobre eqüidade no processo: ouvir o outro lado, prover argumentos para suas ações, encontrar algum mecanismo para julgar reivindicaçôes morais conflitantes. Afirma, portanto, que a "justiça global não é algo que pode ser 
deduzido de princípios racionais nem pode ser resultado de uma única visão de mundo, religiosa ou secular; é, ao contrário, um produto negociado do diálogo e de deliberação e, portanto sempre sujeito a revisão reavaliação" (2003: 44). ${ }^{2}$

Para resumir os argumentos sobre os desenvolvimentos normativos da Escola Inglesa e como isso impacta em sua análise dos problemas políticos atuais. Com a perspectiva solidarista ganhando cada vez mais terreno dentro da Escola suas análises: têm uma noção holística de agência analisando a interação de atores estatais com os não-estatais (Buzan 2004; Hurrell, 2003; Dunne e Wheeler, 2004); enfatizam a indivisibilidade entre segurança e direitos humanos (Dunne e Wheeler, 2004); afirmam a necessidade de se analisar o conteúdo moral da política externa dos Estados (Linklater e Suganami, 2006; Wheeler e Dunne, 1998 e 2003; Dunne 2004).

\section{Sociedade Internacional no pós-11 de Setembro}

Nos anos 90, a Escola Inglesa focava nas crises humanitárias e utilizava com um dos principais instrumentos de análise a distinção de Bull entre pluralismo e solidarismo. No pós-11 de Setembro, temas como: o impacto da unipolaridade americana nas instituições internacionais; sociedade ou hierarquia; império ou hegemonia; terrorismo; impacto da sociedade mundial na internacional; imunidade dos não-combatentes; guerra justa, entre outros, são correntes nas recentes análises da Escola. Alguns destes são temas trazidos pela nova conjuntura, entretanto a grande maioria é parte constitutiva da abordagem da sociedade internacional - o outro nome pelo qual a Escola Inglesa também é conhecida. Nesta seção serão examinados alguns trabalhos recentes de autores da Escola Inglesa afim analisar como tal abordagem pode nos ajudar a entender a atual sociedade internacional.

Ao discutir a questão do progresso e seus limites, Andrew Linklater destaca um ponto importante deste novo contexto internacional com relação aos anos 90 ao comentar que "depois do otimismo cauteloso dos últimos anos, que é evidente em Wheeler (2000), provavelmente a tendência dominante na Escola Inglesa será enfatizar a escala de obstáculos para a criação de uma sociedade internacional solidarista" (Linklater e Suganami, 2006: 146). Linklater (ibid.: 145), argumenta que o fim da era bipolar pode ter removido alguns dos constrangimentos para o desenvolvimento de uma ordem mundial solidarista, mas uma clara conseqüência é a preponderância dos ideais políticos e econômicos do ocidente liberal inseridos em uma era de hegemonia americana quando a decisão de fazer uma "guerra preventiva" e de deslocar a ONU no processo, tem efetivamente restringido as fronteiras da sociedade internacional.

2 Afinal, como nos ensina o filósofo cosmopolita Kwame Anthony Appiah sobre os desacordos morais: "Se vamos encorajar um engajamento cosmopolita e um diálogo moral de pessoas através de sociedades, nós devemos esperar tais desacordos: afinal de contas, eles ocorrem dentro das sociedades. (...) Porque a linguagem moral é um texto aberto e essencialmente contestável, mesmo pessoas que compartilham um vocabulário moral têm muito sobre o que brigar" (2006: 46 e 60 ênfases no original). 
Os recentes trabalhos de Tim Dunne refletem esse maior pessimismo por parte dos solidaristas, que, como vimos, geralmente tendem a ser mais otimistas quanto à possibilidade de princípios expansivos de justiça, como intervenção humanitária, poderem ser promovidos sem que a ordem seja posta em risco. Dunne (2003: 303) começa afirmando que o novo padrão de crise e guerra iniciado pelo ataques terroristas em Nova York e Washington em setembro de 2001 e sustentado pelas guerras contra o Afeganistão e o Iraque, provê um novo contexto em que deve ser reavaliada a afirmação da Escola Inglesa de que a sociedade internacional é um importante elemento na realidade da política mundial. E pergunta: Até aonde a sociedade internacional pode ser mantida dentro de um sistema hierárquico?

Dunne quer problematizar a relação entre sociedade e hierarquia, que para a maior parte das abordagens tradicionais sempre foi vista como algo resolvido. Destaca que historicamente sempre houve graduações de hierarquias. O quê é diferente no pós-11 de Setembro? Ele dá duas respostas. Em primeiro lugar, a escala da superioridade dos EUA. Em segundo, a ideologia do excepcionalismo que guia a política externa e de segurança dos EUA (ibid.: 305). Ao recolocar a questão de Bull, se o elemento de sociedade continua presente hoje, afirma que é importante distinguir entre uma noção fina de sociedade internacional e outra densa. Para ele, a noção fina claramente está presente, pois os Estados continuam se reconhecendo como membros e os Estadistas não deixarão de invocar a linguagem de uma "comunidade internacional". Contudo, se operarmos com uma noção densa da sociedade internacional, cujo principal propósito é a regulação ou eliminação de formas de guerras que ameaçam a ordem internacional, então há boas razões para temermos que o elemento de sociedade esteja ausente da política mundial (ibid.: 306).

Dunne (ibid.) vê como necessário retomar o tema sobre a possibilidade de existência da sociedade internacional sem uma balança de poder. Destaca que as principais ameaças para a concepção "densa" da sociedade internacional são a ausência de uma balança de poder e a falta de consenso entre as potências. Fazendo um paralelo com a "revolta contra o ocidente", que Bull via como uma das principais ameaças à sociedade internacional, Dunne afirma que hoje a principal ameaça parece ser uma revolta contra as instituições da sociedade internacional por parte dos EUA. Sustenta que essa é a grande questão, pois o que importa não é o ato de violar as regras per se - isso acontece em todas as ordens sociais - mas o fato dos representantes americanos procurarem desafiar as regras. E chama a atenção para o fato de Bull sempre nos lembrar que disputas sobre as regras do jogo são perigosas, pois significa grandes disputas sobre legitimidade. Até agora a administração Bush tem sido capaz de quebrar normas acordadas sobre detenção e tratamento dos prisioneiros (2005a: 166). ${ }^{3}$

3 Outro teórico solidarista da Escola Inglesa analisou este ponto com relação às baixas civis na invasão do Afeganistão, ver Wheeler (2002). 
Após fazer uma breve análise histórica da ordem hierárquica vestfaliana, Tim Dunne afirma que aquilo que diferenciava a clássica sociedade internacional européia era que seus membros concordavam em aceitar a natureza legítima da ordem hierárquica e estendiam os mesmos privilégios reciprocamente. Nesse ponto pergunta: Os membros da sociedade internacional hoje estão dispostos a aceitar os privilégios especiais que os líderes dos EUA reclamam para si? Se a resposta é não, então estamos na melhor das hipóteses em um mundo em que uma fina ou fraca sociedade coexiste com uma hierarquia (2005b: 76). ${ }^{4}$

Dunne salienta que se as identidades formam os interesses como nos dizem os construtivistas, então há a necessidade de se analisar a questão da identidade para se examinar o caráter do poder americano e se sua manifestação é compatível com as normas e instituições da sociedade internacional. Para ele devemos considerar de início, o fato de que o poder dos EUA não conhece restrição. Portanto acredita que é um equívoco ver os EUA com a única superpotência ou a última grande potência restante, pois estas categorias pressupõem a existência de outros pólos no sistema. Por esta razão, acredita que o termo "hiperpotência" melhor captura a extensão da primazia americana. Acredita que, quando a hiperpotência começa a impor a lei aos outros e, ao mesmo tempo, isenta-se de qualquer autoridade fora do Estado, então ela cruzou a fronteira que separa a sociedade da hierarquia (2003: 308). Dunne parece aceitar que o poder norte-americano é imperial - em outro trabalho ele chega a se referir aos EUA como "nova Roma” (2004: 908). Ao menos no plano jurídico, uma vez que sua soberania não admite nenhuma autoridade maior para fazer e executar leis. Aponta que a base jurídica do caso do uso da força contra o Iraque se aproxima dessa concepção imperial da lei. Em outubro de 2002 o presidente Bush afirmou que, com a resolução conjunta sobre o Iraque, o Congresso tinha autorizado o uso da força. Por isso, concorda com a conhecida designação de Raymond Aron dos EUA como uma "república imperial". Segundo Dunne o termo é útil para começar a responder à questão de como é

4 Sobre a questão dos EUA reclamarem direitos especiais para si, Barry Buzan afirma que esse é um comportamento de política de poder que pode parecer anti-social para os padrôes estabelecidos, mas certamente não é asocial. Mesmo quando é unilateral envolve comunicação e uma constante preocupação com as regras. É uma tentativa de mudar a estrutura social, não de se colocar fora dela (2005: 187). Uma análise nesse viés é empreendida por Justin Morris que discorrendo sobre a maneira como os EUA articularam o direito de preempção no contexto pós-11 de Setembro destaca que a diplomacia americana argumentou não que suas ações se conformavam com o existente quadro normativo, mas sim que o quadro normativo requeria emendas para poder refletir as realidades políticas, materiais e tecnológicas do século XXI. Nesse sentido, Morris afirma que devemos ver a administração Bush como inovadora de normas e não como um fora da lei para podermos apreciar as verdadeiras implicações do recente conflito no Iraque. Nas mãos dos neoconservadores a maneira como conduzem a política externa e seus desejos de fazerem mudanças normativas é motivada por uma visão idealista da relação entre cidadão, Estado e sociedade internacional e não por realpolitik. E faz a importante observação de que as abordagens materiais das relaçōes internacionais não podem explicar os atuais objetivos da política externa dos EUA, e nem as relações internacionais de maneira geral, porque elas são essencialmente normativas. Por esta razão, a atual política externa dos EUA e as repostas a ela só podem ser entendidas dentro do contexto mais amplo da evolução da sociedade internacional (Morris, 2005: 279-80). Este último ponto será retomado na conclusão. 
possível para uma democracia constitucional baseada no estado de direito agir de maneira a enfraquecer estes mesmos valores internacionalmente.

Retoma mais uma pergunta de Bull: Quantos Estados devem sair da sociedade internacional antes de podermos dizer que ela deixou de existir? A resposta dada pelo trabalho de Dunne (2003: 316) é "um". Pois ele vê que na corrida a guerra do Iraque os EUA momentaneamente "se retiraram" da sociedade internacional. Entre 11 de Setembro de 2001 e 20 de março de 2003 os EUA parecem estar jogando por regras diferentes. Enumera quatro fatores que podem contribuir para a interpretação dos EUA como uma hiperpotência que é incompatível com as regras e instituições que são tidas como vinculantes para os membros da sociedade internacional. Primeiro, a emergência de um entendimento altamente permissivo do direito de autodefesa. Segundo, o argumento afim de que a ação preemptiva é legitimada mesmo quando nenhuma ameaça iminente foi demonstrada. Terceiro, a hiperpotência é contra estender a outros quaisquer dessas justificativas para o uso da força. Quarto, os EUA continuam a ver as restriçōes jurídicas domésticas na ação internacional como sendo mais importante que o direito internacional. Juntos esses fatos sugerem que uma linha de cisão se abriu entre os EUA e a sociedade internacional hoje.

Para concluir pergunta, sob quais circunstâncias podem os EUA reintegrar a sociedade internacional? À medida que os EUA gerenciarem a ordem por princípios hobbesianos, em que se colocam acima das leis, ocuparão a posição como o principal Estado em um sistema hierarquicamente ordenado que está fora da sociedade internacional. Na medida em que os EUA gerenciarem a ordem por princípios lockeanos de criação e imposição das leis às quais todos os soberanos consentem e estão vinculados (incluindo a hiperpotência), então estarão dentro das fronteiras da sociedade internacional. E afirma que este é o momento para a Escola Inglesa confrontar a relação entre sociedade e hierarquia (ibid.: 317$){ }^{5}$

5 Uma pergunta importante a considerarmos é: Como uma abordagem a partir dos postulados da Escola Inglesa, explicaria a adesão quase incondicional da Grã-Bretanha à política dos EUA no Iraque? Para Tim Dunne (2004) a resposta passa pelo ressurgimento da identidade Atlanticista que está moldando a estratégia de segurança britânica depois de 11 de Setembro. As declaraçóes de Tony Blair de comprometimento com os EUA mostram o que essa relação significa para o papel da Grã-Bretanha no mundo. Dunne ressalta que tratar a parceria apenas como "business as usual" que decorre da "relação especial" entre a Grã-Bretanha e os EUA não é algo óbvio pois o Partido Trabalhista tinha fortes expressões de internacionalismo na primeira parte de seu período no poder e, muito além do alcance da política doméstica, mudanças no sistema internacional pode ter feito a Grã-Bretanha reexaminar suas alianças internacionais. Assim ele se propõe a analisar se a estratégia de dependência com os EUA que pode ter sido um caminho racional no mundo bipolar é capaz de atingir os objetivos da política externa britânica em um mundo ordenado de maneira muito diferente.

O autor se volta para uma série de documentos publicados pelo governo britânico em 2003 e 2004 sobre política externa e de segurança. Salienta que tais publicaçōes no lugar de encararem as novas realidades de um mundo dominado por uma inquieta potência com um poder descomunal, são totalmente evasivas e contraditórias. Afirma que o leitor é levado para um universo paralelo onde não existem escolhas difíceis a serem feitas entre alinhamento com a Europa ou com os EUA, onde agir fora do Conselho de Segurança da ONU pode ser reconciliado com multilateralismo, e meios malignos podem ser reconciliados com fins benignos. "O primeiro ministro e seus conselheiros precisam de uma estratégia de segurança revisada que seja apoiada em outra concepção da identidade britânica e propósito moral” (2004: 894). 
Outro autor que usa a abordagem da Escola Inglesa para examinar a atual sociedade internacional é Galia Press-Barnathan (2004), do departamento de RI da Hebrew University of Jerusalem. Seu ensaio tem dois objetivos: primeiro, examinar a política externa dos EUA que levou à guerra no Iraque pela lente do clássico livro de Bull, The Anarchical Society, e, em segundo lugar, explorar em um sistema unipolar hegemônico a relevância e o poder dos mecanismos institucionais que supostamente devem preservar a sociedade internacional, de acordo com Bull.

Começa por analisar os cinco mecanismos institucionais por meio dos quais, segundo Bull, a ordem é alcançada e protegida. Balança de poder: destaca que um dos elementos desta instituição é a dissuasão (deterrence); Direito internacional; diplomacia; O gerenciamento da ordem pelas grandes potências; e, guerra. Seu ensaio pretende analisar o status de três desses mecanismos no pós-11 de Setembro: dissuasão, o gerenciamento pelas potências e o papel da diplomacia multilateral.

Com relação ao mecanismo da dissuasão, Press-Barnathan (ibid.: 199-203) destaca que devido às potenciais conseqüências devastadoras da atual proliferação de armas de destruição em massa e a aquisição destas por grupos terroristas, tornouse necessário deter não apenas o uso de tais armas (a antiga lógica da guerra fria), mas também o seu desenvolvimento e aquisição. Deter tais ações pela ameaça da força deu lugar à ascensão do uso da preempção (na verdade querendo dizer guerra preventiva). A ameaça de intervir é justificada pelo argumento de que o fortalecimento de tais grupos terroristas não-estatais coloca em risco a própria existência da sociedade internacional. Contudo, uma vez que cabe a um Estado

A partir destas críticas contrasta uma estratégia instrumental com uma esclarecida. Esta rejeita o cálculo entre meios e fins em favor de mostrar a conexão entre identidade e interesses. Observa que o conceito de identidade constitui uma importante ligação entre o contexto estrutural em que todos os atores se encontram e os vários interesses articulados por eles. O atual pensamento em segurança estratégica britânica não faz a ligação entre quem são os britânicos e como "eles" devem agir no mundo. Afinal, a Grā-Bretanha é um Estado civilizado que busca agir de maneira a minimizar os danos e promover propósitos cosmopolitas ou a GrãBretanha - ou melhor, as elites que tomam decisōes em nome do povo - é um Estado que quer manter os privilégios (e as responsabilidades) de ser uma grande potência? O que surpreende nos documentos oficiais é a ausência de reflexão sobre os possíveis papéis existentes para a Grã-Bretanha na emergente ordem unipolar (Dunne, 2004: 894).

Dunne quer chamar a atenção para o fato de que o Atlanticismo (a escolha de alinhamento aos EUA) precisa ser repensado diante das novas configuraçōes mundiais. Diante das novas circunstâncias tornou-se impossível para Blair agir como uma ponte entre os "velhos europeus" e os "novos conservadores". Argumenta, portanto, que ao se alinhar "ombro a ombro" com os americanos, a Grā-Bretanha corre o risco de enfraquecer vários de seus objetivos de "prioridades estratégicas", como, por exemplo, fortalecer o Estado de direito; reformar a ONU; desenvolver valores liberais sustentáveis; boa governança e direitos humanos. Sendo um teórico solidarista de viés liberal e, dessa maneira, sempre analisando se o conteúdo moral da política externa está afinado com princípios internacionalista, Dunne afirma que a Grā-Bretanha poderia ter calculado seus interesses de maneira diferente se tivesse percebido a incompatibilidade fundamental entre Atlanticismo e internacionalismo. Ao contrário, o primeiro ministro se ateve ao mito de que o poder dos EUA poderia ser usado pelo bem da sociedade internacional como um todo. Isto não representa um trágico dilema aonde o governo britânico foi posto em uma "situação impossível" pelas decisōes tomadas em Washington, mas uma leitura equivocada do poder e princípios. Em última instância, estratégia é sobre fazer escolhas, mesmo se as circunstâncias em que são feitas não são de nossas escolhas.

Dunne conclui (2004: 909) que a linha de cisão entre os EUA e a Europa passa pelo Canal da Mancha e não pelo Atlântico. 
- os EUA - decidir unilateralmente quando a guerra preventiva é necessária, essa abordagem de "salvar" a sociedade de Estados é claramente problemática. Observa que o hegemon só pode moldar e remodelar as regras do jogo se tiver suficiente legitimidade ou "soft power". ${ }^{6}$ E conclui que é exatamente esse tipo de poder que parece estar em declínio.

No que se refere ao papel da diplomacia multilateral, o autor faz observaçóes importantes que, a meu ver, questionam a visão do senso comum que coloca a ONU como irrelevante e incapaz de restringir o "império":

Os EUA não escolheram inicialmente tentar operar através da ONU com o propósito de "passar pelos procedimentos". Acadêmicos como Ikenberry (2001) demonstraram como o uso do poder via instituiçóes internacionais pode ser mais efetivo porque aumenta a legitimidade das açóes do Estado poderoso e reduz os custos de tais ações. A administração dos EUA provavelmente não teria começado o processo de negociação com os outros membros do Conselho de Segurança sobre a resolução se não pensasse que poderia usar sua influência para, de maneira bem sucedida, passar tal resolução. O fato dos EUA terem se engajado em um esforço extensivo para passar a resolução autorizando a guerra contra o Iraque e mesmo assim ter falhado em conseguir um segundo acordo, além da Resolução 1441, explicitamente apoiando a opção de guerra, sugere que os EUA tinham menos poder do que a sua administração pensava (2004: 206).

Para Press-Barnathan, pode-se oferecer um argumento ainda mais provocativo e sugerir que se os EUA tivessem sido capaz de convencer (ou subornar) um número suficiente de Estados no Conselho de Segurança para votar pela guerra, tal façanha teria demonstrado o seu poder esmagador, bem como a irrelevância da ONU. Afirma que os críticos estarão certos em apontar que a ONU não foi capaz de evitar a guerra. Mas a falta de vontade desta instituição global de se curvar mesmo sob pressão americana permitiu que um grande número de Estados pudessem expressar coletivamente sua oposição à guerra e destacar a natureza unilateral do comportamento americano. O episódio mostrou que a ONU tem uma influência limitada sobre o hegemon mas, ao mesmo tempo, também mostrou o importante fato de que ela não é apenas um carimbo para a política dos EUA. Estes devem dar à ONU maior relevância quando no futuro tratar de outras questôes políticas além das decisões de guerra:

6 Sobre a relação entre poder e a capacidade ou não de moldar as regras do jogo, ver Hurrell (2000) Morris (2005) e Wheeler (2004). Um tratamento extensivo e sofisticado do assunto é oferecido por Michael Byers (1999, especialmente os três primeiros capítulos), no que diz respeito à influência das normas consuetudinárias na equação do poder. Martti Koskenniemi (2001) com a sua habitual verve crítica e anti-mainstream analisa o papel normativo dos teóricos de RI e do Direito Internacional nessa relação. 
O debate envolvendo a política em torno do Iraque também refletiu outro ponto interessante. Especialmente em um mundo unipolar, no qual as atuais disparidades de poder entre os EUA e outras potências são enormes, o gerenciamento da ordem pelas grandes potências e a diplomacia multilateral são interligados. Foi no contexto institucional da ONU que os EUA negociaram com outras grandes potências do sistema (França, Alemanha, Russia, China) sobre a natureza e os limites de seu gerenciamento conjunto da ordem internacional. Bull argumentava que a ordem é mantida através da adoção de efetivas regras de conduta para guiar o comportamento dos Estados. O debate na ONU foi basicamente uma expressão da tentativa do hegemon de interpretar regras preexistentes de uma nova maneira e de legitimar esta interpretação. A tentativa falhou (2004: 206). ${ }^{7}$

Press-Barnathan (ibid.: 209) conclui reafirmando que o objetivo do trabalho era examinar a maneira em que os mecanismos institucionais que devem preservar a sociedade de Estados foram testados pela nova realidade de um mundo unipolar. Foi proposto que a diplomacia mutilateral via ONU não sofreu o golpe fatal que alguns disseram que sofreu e, de fato, a resistência às ações dos EUA serviram para destacar à medida que a atual sociedade internacional é mais forte do que pensávamos. Apesar da guerra no Iraque ter mostrado a clara dominação militar americana, o caminho para a guerra e o seu resultado na verdade destacam as limitações da hegemonia dos EUA. Essas limitações não apontam para o fortalecimento do viés unilateralista americano mas, ao contrário, elas na verdade indicam a importância do gerenciamento compartilhado das presentes ameaças à ordem internacional.

Por fim, chegamos ao exame das equilibradas análises de Andrew Hurrell. Ele busca analisar o papel das normas jurídicas e morais nos nossos entendimentos sobre a política mundial pós-11 de Setembro. Por isso, destaca as palavras do presidente George W. Bush em uma conferência de imprensa em 17 de setembro de 2001 em resposta a uma questão que dizia respeito as táticas das forças americanas na guerra ao terrorismo: "Não há regras" (there are no rules). Para Hurrell (2002: 185), é instrutivo perguntar "que regras?", pois provê uma maneira de examinar os eventos de 11 de Setembro e os seus resultados; de avaliar o que mudou ("uma nova, nova ordem mundial"? "um novo tipo de guerra"? "um novo tipo de América"?); e provê uma base para o julgamento político e moral.

Chama a atenção para o fato de que as reações ao 11 de Setembro e o desenrolar da guerra ao terrorismo devem servir para nos lembrar dos múltiplos papéis das normas, regras e instituições. Dentre estes vários papéis, destaca três: primeiro, as normas não simplesmente constrangem mas também capacitam e

7 Christian Reus-Smit (2004: 2) destaca que essa foi a pior derrota diplomática dos EUA em cinqüenta anos. Argumenta ainda que a existência de uma superpotência com extraordinária preponderância material, mas com uma frustrante influência política constitui um paradoxo central de nosso tempo. 
conferem poder à ação. Segundo, é praticamente impossível separar o cálculo das conseqüências de nossos entendimentos das normas jurídicas e morais e dos poderes constitutivos, mobilizadores e legitimadores dessas normas. Terceiro, as normas são centrais para julgar e avaliar a ação (ver também Hurrell, 2002a).

Hurrell conta que como no segundo semestre de 2001 a administração americana buscou formar uma ampla coalizão e procurou o aval das instituições internacionais para sua ação no Afeganistão, muito se falava de como uma administração originalmente unilateralista tinha sido forçada a se engajar no multilateralismo. Discorre sobre duas abordagens teóricas que podem interpretar esse suposto engajamento multilateral. Em primeiro lugar, o institucionalismo neoliberal que foca nos benefícios que as ações por meio das instituiçôes podem trazer. Em segundo lugar, o solidarismo que foca no aumento da ambição jurídica (e moral) da ordem internacional. No entanto, Hurrell (2002: 190) destaca que ambas as abordagens enfrentam problemas uma vez que a administração americana se mostra cada vez mais resistente a aceitar a lógica destas posições teóricas. Se formos examinar o porquê disso, entramos no caráter da hegemonia americana. E aí vemos, nesse ponto, que na posição em que se encontram os EUA eles são capazes de resistir às pressões constitucionalistas do sistema. Há também a longa tradição de ambivalência com relação às instituições internacionais, revelando um multilateralismo seletivo.

Há um choque entre as regras jurídicas e a lógica política em que estamos inseridos, e Hurrell ressalta ainda que as tensões e contradições da ordem dos anos 90 , supostamente mais liberal, ${ }^{8}$ foram exacerbadas. Entretanto, por outro lado, ajuda a destacar os aparentes limites de uma ordem baseada na imposição. Daí Hurrell (ibid.: 202) observar a importância da legitimidade como o ponto de encontro pragmático entre a efetividade política e a necessidade de um consenso moral.

Com relação à caracterização do poder americano, Hurrell (2005: 30) não concorda que seja um império, pois o conceito de hegemonia é analiticamente mais útil. Pois, dessa maneira, o "analista é forçado a concentrar-se diretamente em questôes cruciais tais como negociação, legitimidade e a necessidade do hegemon conseguir adeptos e seguidores" (ver também Clark, 2005: 239). Hurrell rejeita a visão puramente material do poder e chama a atenção para a dificuldade de articulá-lo com outras modalidades de poder para então obter ganhos reais sem comprometimentos dos custos. Nesse sentido, menciona Clausewitz e afirma que

8 “(...) a legitimidade do multilateralismo liberal da década de 1990, já foi questionada por muitos Estados (e movimentos sociais), com o desenrolar da década. Para esses, a retórica do multilateralismo liberal encobre seu real caráter hierárquico, prescritivo e freqüentemente coercitivo. Os resultados substantivos pareceram estar em favor do mais poderoso: segurança coletiva havia se tornado segurança seletiva; a agenda de direitos humanos beneficiava a democracia, e direitos civis e políticos, mas negligenciava direitos econômicos e sociais, e ignorava pedidos por maior justiça econômica; e, apesar de a globalização econômica ser altamente promovida, pouca atenção era dada às suas insatisfações e desvantagens” (Hurrell, 2005: 52). Ver também Woods (2003) e O’Brien et al. (2000). 
se pode ganhar uma guerra, mas isso pode não ser uma vitória política, como é nítido no caso do Iraque (Hurrell, 2007):

As fontes de poder dos Estados Unidos são de fato enormes. Mas o que é mais notável é a instabilidade desse poder, suas incertezas e a dificuldade perene de se traduzir poder em resultados desejados, especialmente duráveis em mundo cada vez mais complexo (...). A linha-dura do "nós podemos fazer isso sozinhos" está claramente equivocada. Mas a versão hegemônica liberal, "nós podemos fazer isso juntos" depende de quem 'nós' somos, do que 'isso' significa, e do que se quer dizer com 'juntos' (2005: 51 e 52).

\section{Considerações Finais}

Ao analisarmos, na primeira parte, a questão da ordem e justiça e, posteriormente, ao examinarmos os trabalhos recentes da Escola Inglesa sobre o pós11 de Setembro vimos que a abordagem mostra-se valiosa pois foca nos elementos normativos e na maneira como esses interagem com os elementos materiais. Levantando grandes e importantes questôes que não podem ser tratadas dentro de uma perspectiva puramente materialista, estruturalista, e que reduz a noção de agência na política internacional apenas aos Estados. Essa limitada noção de agência perde de vista as dinâmicas da sociedade mundial e como essa impacta nas estruturas de significados (social, jurídica e institucional) e nos princípios básico da sociedade internacional. Um ponto extremamente relevante no atual ordenamento internacional onde algumas das principais ameaças à sociedade de Estados advêm de grupos terroristas. A percepção por parte dos recentes autores da Escola Inglesa de que os desafios da ordem do pós-Guerra Fria não podem mais ser tratados sem levar em consideração os desenvolvimentos da sociedade mundial é uma das principais inovaçôes pela qual a Escola vem passando nos últimos anos (Souza, 2006).

Os temas tratados nos trabalhos analisados demonstram essa abordagem: a importâncias das normas e regras, questôes de legitimidade, as tensões entre ordem e justiça, a importância das instituições internacionais, governança global e globalização, direito humanitário internacional, entre outros.

Sobre o caráter e a identidade do poder americano a abordagem mostra a dificuldade de se manter uma ordem baseada na imposição, nas dificuldades do poder material traduzir isto para ganhos reais e vitórias políticas e, conseqüentemente, exacerbando as tensões, contradições e deformidades inerentes à ordem internacional. Como sustenta Hurrell (2002: 202-3) uma "hegemonia efetiva requer a aceitação pelos outros da liderança e autoridade do hegemon", e que as reivindicações americanas de excepcionalismo têm, até agora, intensificado comprometimentos políticos e morais contra-hegemônicos ao invés de uma aceitação da habilidade da grande potência de impor a lei, onde a hegemonia eficiente em último caso se apoia. Obviamente, a resposta contra-hegemônica 
baseia-se em grande parte em tentar persuadir os EUA de seguirem com seus próprios valores liberais (Linklater e Suganami, 2006: 195). Dessa forma, a Escola Inglesa traz a questão para a necessidade da legitimidade e o fortalecimento das instituições internacionais.

Sobre o ponto levantado por Justin Morris (2005: 279-80, ver nota 5) sobre os atuais objetivos da política externa dos EUA serem essencialmente normativos e, por esta razão, as repostas a ela só poderem ser entendidas dentro do contexto mais amplo da evolução da sociedade internacional, Linklater (Linklater e Suganami, 2006: 149) faz uma importante observação que demonstra bem esse caso. Ele afirma que os ataques terroristas de 11 de Setembro são parte da contínua "revolta contra o ocidente", que Bull (1985) via como parte inerente da expansão da sociedade internacional. Hedley Bull acreditava que o futuro da sociedade internacional, em grande parte, dependia da maneira em que as potências ocidentais respondessem a essa revolta. Ainda continua dependendo.

\section{Referências bibliográficas}

APPIAH, Kwame Anthony. Cosmopolitanism: Ethics in a World of Strangers. New York: Norton, 2006.

BULL, Hedley. "The Grotian Conception of International Society”. In H. Butterfield and M. Wight (eds.), Diplomatic Investigations: Essays in the Theory of International Politics. London: Allen and Unwin, 1966. p. 51-73.

. "The Revolt Against the West". In H. Bull and A Watson (eds.), The Expansion of International Society. New York: Oxford University Press, 1985. p. 217-228.

"Martin Wight and the Theory of International Relations", in Martin Wight, International Theory: The Three Traditions (Edited by Gabriele Wight and Brian Porter). London: Leicester University Press, 1991. p. ix-xxiii. 1995 [1977].

The Anarchical Society - A Study of Order in World Politics. $2^{\text {nd }}$ ed., London: Macmillan,

BUZAN, Barry. From International to World Society?: English School Theory and the Social Structure of Globalisation. Cambridge: Cambridge UP, 2004.

. "Not Hanging Separately: Responses to Dunne e Adler". Millennium, vol.34, no1, 2005. p.183-194.

BYERS, Michael. Custom, Power and the Power of Rules: International Relations and Customary International Law. Cambridge: Cambridge UP, 1999.

CLARK, Ian. Legitimacy in International Society. Oxford: Oxford UP, 2005.

DUNNE, Tim. "Society and Hierarchy in International Relations", International Relations, vol. 17, no 3, 2003. p. 303-320.

“'When the shooting starts': Altanticism In British security strategy", International Affairs, vol. 80, no5, 2004. p.893-909.

. "System, States and Society: How Does It All Hang Together?”. Millennium, vol.34, no1, 2005a. p. 157-170. 
. "The New Agenda", in Alex J. Bellamy (ed.) International Society and its Critics. New York: Oxford UP, 2005b. p.67-79.

HURRELL, Andrew. "International Law and the Changing Constitution of International Society". In Michael Byers (ed.), The Role of Law in International Politics: Essays in International Relations and International Law. New York: Oxford UP, 2001. p.327-347.

. "'There are no Rules' (George W. Bush): International Order after September 11”, International Relations, vol. 16, nº2, 2002. p. 185-204.

. "Norms and Ethics in International Relations". In Walter Carlsnaes et al. (eds.), Handbook of International Relations, London: Sage, 2002a. p. 137-54.

"Order and Justice in International Relations: What is at Stake?", in Rosemary Foot et al (eds.), Order and Justice in International Relations, New York: Oxford UP, 2003. p.24-48.

Pax Americana ou o Império da Insegurança?, Rev. Bras. Polit. Int, vol. 48, nº2, 2005. p. 30-54. 13.4.2007.

"Emerging Powers and Global Governance". Palestra proferida na PUC-Rio, em

KOSKENNIEMI, Martti. "Carl Schmitt, Hans Morgenthau, and the Image of Law in International Relations. In Michael Byers (ed.), The Role of Law in International Politics: Essays in International Relations and International Law. New York: Oxford UP, 2001. p.17-34.

LINKLATER, Andrew e SUGANAMI, Hidemi. The English School of International Relations: a contemporary reassessment. Cambridge: Cambridge UP, 2006.

MORRIS, Justin. "Normative Innovation and the Great Power". In Alex J. Bellamy (ed.) International Society and its Critics. New York: Oxford UP, 2055. p.265-282.

O'BRIEN, Robert et al. Contesting Global Governance: Multilateral Economic Institutions and Global Social Movements. Cambridge: Cambridge UP, 2000.

PRESS-BARNATHAN, Galia. "The War against Iraq and International Order: From Bull to Bush”. International Studies Review, vol. 6, 2004. p. 195-212.

REUS-SMIT, Christian. "Imagining Society: Constructivism and the English School”. British Journal of Politics and International Relations, vol. 4, n³, 2002. p.487-509.

. American Power and World Order. Cambridge: Polity, 2004.

. “The Constructivist Challenge after September 11", in Alex J. Bellamy (ed.)

International Society and its Critics. New York: Oxford UP, 2005. p.81-94.

SOUZA, Emerson Maione de. A Contribuição e o Desenvolvimento da Escola Inglesa de Relaçôes Inernacionais. Dissertação de Mestrado, IRI/PUC-Rio, 2003 (Disponível no endereço eletrônico: http://www2.dbd.puc-rio.br/pergamum/biblioteca/php/ mostrateses.php? open=1 \&arqtese=0114308_03_Indice.html). Acessado em 28/04/2008. . "A Escola Inglesa no Pós-Guerra Fria: Fechamento, tradicionalismo ou inovação?", Cena Internacional, vol. 8, no 2, 2006. p. 29-62.

"Reavaluating the Contribution and Legacy of Hedley Bull". Brazilian Political Science Review, no prelo.

WHEELER, Nicholas. Saving Strangers: Humanitarian Intervention in International Society. New York: Oxford University Press, 2000. 
"Dying for 'Enduring Freedom': Accepting Responsibility for Civilian Casualties in the War against Terrorism”, International Relations, vol. 16, n 2, 2002 p. 205-225.

. "The Humanitarian Responsibilities of Sovereignty: Explaining the Development of a New Norm of Military Intervention for Humanitarian Purposes in International Society. In Jennifer Welsh (ed.), Humanitarian Intervention and International Relations. New York, Oxford UP, 2004. p.29-51.

e DUNNE, Tim. "The Good International Citizen: A Third Way for British Foreign Policy”. International Affairs, vol.74, n4, 1998. p. 847-70.

e _____"Moral Britannia? Evaluation: the ethical dimension in Labour's foreign policy". Foreign Policy Center. March, 2003. http://fpc.org.uk/fsblob/233.pdf. Acessado em 28/04/2008.

e

"'We the Peoples': Contending Discourses of Security in Human Rights Theory and Practice”. International Relations, vol.18, nº1, 2004. p. 9-23.

WIGHT, Martin. International Theory: The Three Traditions. London: Leicester University Press, 1991.

WOODS, Ngaire. "Order, Justice, the IMF, and the World Bank". In Rosemary Foot et al (eds.), Order and Justice in International Relations, New York: Oxford UP, 2003. p. 80-102.

Recebido em 29 de abril de 2008 Aprovado em 20 de janeiro de 2009

\section{Resumo}

Neste artigo, visa-se a analisar como a abordagem da Escola Inglesa tem examinado a política internacional do pós-11 de Setembro. Em primeiro lugar, analisa-se alguns desenvolvimentos sobre a questão da justiça dentro da Escola, principalmente o destaque à concepção solidarista da sociedade internacional. Posteriormente analisa-se como a Escola Inglesa pode nos ajudar a entender alguns dos principais desafios que a atual unipolaridade impõe à sociedade internacional. Destaca-se os limites de uma ordem baseada na imposição e chama-se a atenção para a questão da legitimidade e do fortalecimento das instituições internacionais.

\section{Abstract}

The article intends to analyze how the English School approach has examined international politics after September 11. It begins by analyzing some developments on the matter of justice that has taken place within the English School, highligning the solidarist conception of international society. Afterwards the article analyses how the English School can help us to understand some of the main challenges that unipolarity poses on international society. It emphasize the limits of an order based on imposition and drives attention to the question of legitimacy and strengthening of international institutions.

Palavras-chave: 11 de Setembro; Escola Inglesa; Legitimidade

Key words: September 11; English School; Legitimacy 